\title{
The Protective Effects of the A/ZJU01/ PR8/2013 Split H7N9 Avian Influenza Vaccine Against Highly Pathogenic H7N9 in BALB/c Mice
}

\author{
Xiao-Xin Wu $\mathrm{W}^{\mathrm{a}}$ Xi-Long Deng ${ }^{\mathrm{b}}$ Dong-Shan Yua Wei Yao ${ }^{\mathrm{a}}$ Hui-Lin Ou ${ }^{\mathrm{a}}$

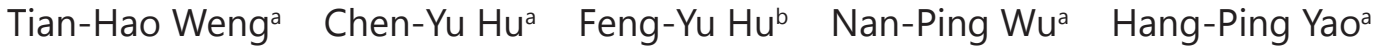 \\ Fu-Chun Zhang ${ }^{\text {b }}$ Lan-Juan Lia
}

aState Key Laboratory for Diagnosis and Treatment of Infectious Diseases, Collaborative Innovation Center for Diagnosis and Treatment of Infectious Diseases, The First Affiliated Hospital, School of Medicine, Zhejiang University, Hangzhou, 'buangzhou Eighth People's Hospital, Guangzhou Medical University, Guangzhou, Guangdong 'Zhejiang Tianyuan Bio-Pharmaceutical Co., Ltd. China

\section{Key Words}

Split H7N9 vaccine • MF59 adjuvant • Highly pathogenic H7N9 • Protective immune responses

\begin{abstract}
Background/Aims: Since the first case of novel H7N9 infection was reported, China has experienced five epidemics of H7N9. During the fifth wave, a highly pathogenic H7N9 strain emerged. In order to assess whether the H7N9 vaccine based on A/Zhejiang/DTIDZJU01/2013(H7N9) was effective in protecting against highly pathogenic H7N9, we conducted this study. Methods: Groups of mice were immunized twice by intraperitoneal injection with $500 \mu \mathrm{l}$ of either split vaccine alone or MF59-adjuvanted vaccine. Serum was collected 2 weeks after the second vaccine booster. The hemagglutinin inhibition test was conducted on vaccine seed and highly pathogenic $\mathrm{H} 7 \mathrm{~N} 9$ to evaluate the neutralization of highly pathogenic H7N9. We also immunized mice and challenged them with highly pathogenic H7N9. Mice were observed for illness, weight loss, and death at 1 week and 2 weeks post-infection. Then, the mice were sacrificed and lungs were removed. Antibody responses were assessed and pathological changes in the lung tissue were evaluated. Results: The ability of serum to neutralize highly pathogenic $\mathrm{H} 7 \mathrm{~N} 9$ was reduced. In mice, highly pathogenic H7N9 was more virulent than A/Zhejiang/DTID-ZJU01/2013(H7N9). After challenge with highly pathogenic H7N9, all mice died while mice challenged with A/Zhejiang/DTID-ZJU01/2013(H7N9) all recovered. The A/ZJU01/PR8/2013 split H7N9 avian influenza vaccine was able to protect against infection with highly pathogenic H7N9 in mice, with or without MF59. Moreover, H7N9 vaccine adjuvanted with MF59 produced high antibody levels, which lead to better
\end{abstract}

$\mathrm{XX}$. Wu and XL. Deng contributed equally to this article.

Hang-Ping Yao, Professor And Fu-Chun Zhang, Professor, Lan-Juan Li, Professor

KARGER
State Key Laboratory for Diagnosis and Treatment of Infectious Diseases, Zhejiang

(China); Guangzhou Eighth People's Hospital, Guangzhou Medical University,

Guangzhou, Guangdong, (China); Tel 86-571-87236582

E-Mail yaohangping@zju.edu.cn; gz8hzfc@126.com; ljli@zju.edu.cn 


\section{Cellular Physiology Cell Physiol Biochem 2018;46:633-643

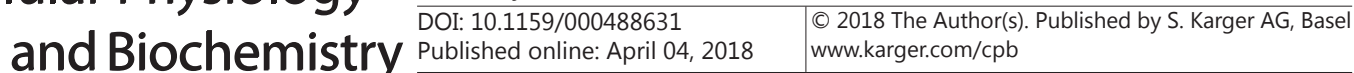

Wu et al.: h7n9 Vaccine Protects Against Highly Pathogenic H7N9

protection. Conclusions: The A/ZJU01/PR8/2013 split H7N9 avian influenza vaccine based on A/Zhejiang/DTID-ZJU01/2013(H7N9) is effective in protecting against highly pathogenic H7N9. H7N9 vaccine adjuvanted with MF59 offers better protection against infection with highly pathogenic H7N9. In order to make the H7N9 vaccine applicable to humans, further clinical trials are required to evaluate MF59 adjuvanted vaccine. Meanwhile, the vaccine strain should be updated based on the highly pathogenic H7N9 gene sequence.

(C) 2018 The Author(s)

Published by S. Karger AG, Basel

\section{Introduction}

Since the first human report of avian influenza A H7N9 virus emerged in eastern China in February, 2013, avian influenza A H7N9 viruses have been shown to cause both high mortality and morbidity [1]. In the following 5 years, five outbreaks of infection were caused by the H7N9 virus in China. Between Feb 19, 2013, and Feb 23, 2017, 1220 laboratoryconfirmed H7N9 infections were reported in mainland China [2]. To date, H7N9 has caused more than 1600 severe human infections. More than 30 provinces, cities, and regions have reported H7N9 infections. Malaysia and Canada have also detected H7N9 cases [3].

Recently, a novel highly pathogenic H7N9 avian influenza A virus (HPAI H7N9) possessing multiple basic amino acids at the cleavage site of the hemagglutinin protein was reported in two human cases in January 2017 [4]. The 2017 isolate also possessed an R292K substitution in the neuraminidase protein, which confers oseltamivir resistance [5]. Animal experiments showed that these novel HPAI H7N9 variants were both highly pathogenic in chickens and lethal to mice. Notably, viruses of human origin were more pathogenic in mice than avian viruses. Now, these novel HPAI H7N9 strains have caused human infection in 3 provinces and poultry farm outbreaks in 8 provinces [6]. Considering the rapid geographical expansion of the HPAI H7N9 viruses, effective control measures are urgently needed [7].

The vaccine plays a very important role in prevention and control of influenza including H7N9. As influenza changes antigenically, the influenza vaccine has to be updated accordingly too. The WHO has suggested A/Shanghai/2/2013 and A/Anhui/1/2013 as the parent strains for generation of the vaccine strains for H7N9. However, there has been no suggested vaccine for highly pathogenic H7N9. Currently, there are no effective vaccines available for HPAI H7N9, which is worrying. We successfully used reverse genetics technology and produced China's first H7N9 viral vaccine. Compared to wild-type H7N9 virus, the virulence and transmissibility of the A/ZJU01/PR8/2013 H7N9 avian influenza vaccine seed strain decreased to levels comparable with PR8 [8]. Moreover, we performed acute toxicity, repeated dose toxicity, and active systemic anaphylaxis tests to evaluate the safety of our H7N9 vaccine in mice. This vaccine completed the immunogenicity and safety testing [9].

MF59, the oil-in-water emulsion, was initially licensed in Europe for use in seasonal influenza vaccine in the elderly [10]. The vaccine is of good safety and immunogenicity. Thus the MF59 adjuvanted seasonal influenza vaccine is a valid option to optimize the control of seasonal influenza. Since that time, both MF59 adjuvanted H5N1 and p2009H1N1 vaccines have also been developed. Safety and effectiveness data was obtained from clinical trials and observation studies. MF59 was identified with the ability to enhance the effectiveness of influenza vaccines [11-14]. MF59 can induce higher, broader, and more persistent antibody responses in adults and particularly in young. MF59 has a good safety profile as vaccine adjuvant and was used in our previous study. The A/ZJU01/PR8/2013 split H7N9 avian influenza vaccine was shown to protect against A/Zhejiang/DTID-ZJU01/2013(H7N9) virus infection [15]. As the H7N9 antigen gene had changed, it was not known whether the previous A/ZJU01/PR8/2013 split H7N9 avian influenza vaccine was effective against these novel HPAI H7N9 strains. In this study, we evaluated the protection afforded by our H7N9 vaccine against the new HPAI H7N9 in vivo and in vitro. 


\section{Cellular Physiology Cell Physiol Biochem 2018;46:633-643 and Biochemistry Published onlıne: April 04, $2018 \quad \begin{aligned} & \text { DOI: 10.1159/000488631 } 2018 \text { The Author(s). Published by S. Karger AG, Basel } \\ & \text { www.karger.com/cpb }\end{aligned}$}

Wu et al.: h7n9 Vaccine Protects Against Highly Pathogenic H7N9

\section{Materials and Methods}

Female BALB/c mice aged 6-8 weeks old were purchased from Shanghai Laboratory Animal Center, China. All animal studies were performed in accordance with the Guide for the Care and Use of Laboratory Animals of Zhejiang Province and the study was approved by the local Ethics Committee. Zhejiang Tianyuan Bio-Pharmaceutical Co., Ltd. (which was affiliated to GSK Vaccine Inc.) provided the MF59 adjuvant (MF59 is a trade mark of Novartis AG and Affiliate Companies). H7N9 nucleic acid quantitative detection kit was purchased from Zhijiang biological technology Co., Ltd. Shanghai. The Madin-Darby canine kidney cell line (MDCK) was obtained from the ATCC (Rockville, MD, USA).

\section{The collection of serum}

Groups $(\mathrm{n}=8)$ of male BALB/c mice aged 6-7 weeks old were weighed $(19-21 \mathrm{~g})$ then immunized twice by intraperitoneal injection with $500 \mu \mathrm{l}$ of either split vaccine alone or MF59-adjuvanted vaccine. Two weeks after the immune booster, mice were sacrificed for blood collection after anesthesia. The blood was centrifuged at $5000 \mathrm{rpm}$ for $10 \mathrm{~min}$ to obtain serum. The serum was stored separately at $-80^{\circ} \mathrm{C}$.

Viruses and vaccine generation

Novel highly pathogenic H7N9 was isolated from a patient in Guangzhou, China in 2017. This novel highly pathogenic H7N9 strain was already uploaded to the influenza gene bank and named A/Guangdong/ HP001/2017(H7N9). The A/Zhejiang/DTID-ZJU01/2013(H7N9) virus was isolated from a patient in Zhejiang Province, China in 2013. The A/ZJU01/PR8/2013 avian influenza vaccine seed strain was made containing hemagglutinin (HA) and neuraminidase (NA) genes from the aforementioned virus and six internal genes from the PR8 virus. Then, the seed virus was grown to a high titer in chick embryos and the virions were purified by centrifugation, inactivated with formalin, and filtered to remove bacteria. The H7N9 split vaccines were produced under Good Manufacturing Practices.

\section{Animal immunizations}

Groups $(n=6)$ of female BALB/c mice aged 6 to 8 weeks old were weighed $(22 \pm 2 \mathrm{~g})$ and then immunized twice by intraperitoneal injection with $500 \mu \mathrm{l}$ of either split vaccine alone or MF59-adjuvanted vaccine at a 2 -week interval. The control group was immunized with PBS. Animal blood was collected via the tail vein on the day before each immunization and virus incubation. All mice were ascertained as having no pre-existing immunity against influenza virus, which was defined as hemagglutinin inhibition (HI) activity $\leq 10$.

\section{Virus inoculation}

The TCID50 (Fifty percent tissue culture infective dose) assay was performed as described previously [8]. Two weeks after the second boost, mice in group $1(n=6)$, group $2(n=6)$, and group $3(n=6)$ were inoculated intranasally with $50 \mu \mathrm{l} 10^{6}$ TCID50 A/Guangdong/HP001/2017(H7N9). The A/Zhejiang/DTIDZJU01/2013(H7N9) strain at the same dose was given to the mice in group $4(n=6)$. PBS of the same volume was given to the mice in group 5 (Table 2). Mice were observed for illness, weight loss, and death 1 and 2 weeks post-infection. Then, the mice were sacrificed and lungs were removed. Part of the lung was fixed in $10 \%$ buffered formalin, while the other part was used to detect levels of virus with quantitative PCR.

\section{Hemagglutinating inhibition titer test}

The four units of the A/Guangdong/HP001/2017(H7N9) and A/Zhejiang/DTID-ZJU01/2013(H7N9) viruses were determined using the hemagglutinating test. Prior to hemagglutinating inhibition titer (HI) tests, heat-inactived serum samples were diluted 1:10, then a two-fold serial dilution series of serum was mixed 1:1 with four units of virus and incubated at $37^{\circ} \mathrm{C}$ for $1 \mathrm{~h}$. Subsequently, $50 \mu \mathrm{l} \%$ chicken erythrocytes were added, mixed, and incubated for $1 \mathrm{~h}$ at room temperature. All agglutination patterns were read within $10 \mathrm{~min}$.

Micro-neutralization (MN) assay

MDCK cells were seeded at $2 \times 10^{4}$ cells/well in 96-well plates and cultured overnight to 80-90\% confluency at $37^{\circ} \mathrm{C}$. Heat-inactived serum samples were diluted 1:10 with PBS, then serially diluted 
Wu et al.: h7n9 Vaccine Protects Against Highly Pathogenic H7N9

two-fold and mixed with $50 \mu \mathrm{l}$ of 100 TCID50 A/Zhejiang/DTID-ZJU01/2013(H7N9) or A/Guangdong/ HP001/2017(H7N9) for $2 \mathrm{~h}$ at $37^{\circ} \mathrm{C}$. Cells were incubated in the presence of TPCK-treated trypsin at $37^{\circ} \mathrm{C}$ for $72 \mathrm{~h}$ post-infection. The presence of virus was detected using a hemagglutination assay.

\section{Immunoglobulin $G$ enzyme-linked immunosorbent assay (IgG-ELISA)}

Ten ng/well H7N9 HA antigen was coated in PBS coating solution (KPL, USA) overnight at $4^{\circ} \mathrm{C}$ on 96-wells of polyvinyl chloride microtiter plates (Falcon, USA). At room temperature, all the wells were coated with 3\% bovine serum albumin (Sigma-Aldrich, USA) and incubated for $2 \mathrm{~h}$ after three washes. Next, wells were washed three times and 2-fold serial dilutions of serum were inoculated in $100 \mu \mathrm{l}$ volumes for $2 \mathrm{~h}$. Plates were again washed five times, and $100 \mu \mathrm{l}$ peroxidase-labeled goat anti-mouse immunoglobulin G (Earthox, USA) was added to each well and incubated for $2 \mathrm{~h}$. After another wash, $100 \mu \mathrm{l} /$ well substrate TMB (KPL, USA) was added and then the reaction was stopped after 8 minutes. Absorbance was measured at the wavelength ratio $450 \mathrm{~nm} / 630 \mathrm{~nm}$. The background average OD value was removed. ELISA titer was determined to be 2.1-fold greater than the average OD value of the negative control cell.

\section{Virus titers and histopathology of lung tissue}

The amount of virus was evaluated by quantitative PCR. Lung tissue was made for hematoxylin eosin (HE) staining. The immunohistological (IHC) test in mouse lung sections was also conducted. Paraffin sections of lungs were de-waxed and then subjected to citrate by heat treatment, and endogenous peroxidase activity was quenched with $0.3 \% \mathrm{H}_{2} \mathrm{O}_{2}$ in methanol. Sections were blocked for $1 \mathrm{~h}$ with $3 \%$ BSA in PBS and incubated sequentially overnight at $4{ }^{\circ} \mathrm{C}$ with 1:400 dilution of polyclonal rabbit anti-H7N9 antibody. Antibody binding was detected using EnVision System reagents (DAKO, Denmark). All slides were counterstained with hematoxylin.

\section{Statistical analysis}

Statistical analyses of data for weight and survival rate were performed by Graphpad Prism 5. Statistical analyses of data for HI titers, MN titers, IgG titers and normalized H7N9 gene expression were conducted using a one-way ANOVA test with Tukey's multiple comparison test. Values were presented as means \pm SEM for indicated sample sizes. P-values $<0.05$ were considered statistically significant.

\section{Results}

HI titer of serum to highly pathogenic H7N9 and vaccine seed

Sera was collected 14 days after the second boost under different immune dosing regimens (Table 1 ). The HI titer of this serum was determined by its action on A/Guangdong/ HP001/2017(H7N9) and the vaccine seed. Antibody responses are shown in Fig. 1. The HI titer of this serum to highly pathogenic H7N9 was significantly reduced compared to the vaccine seed

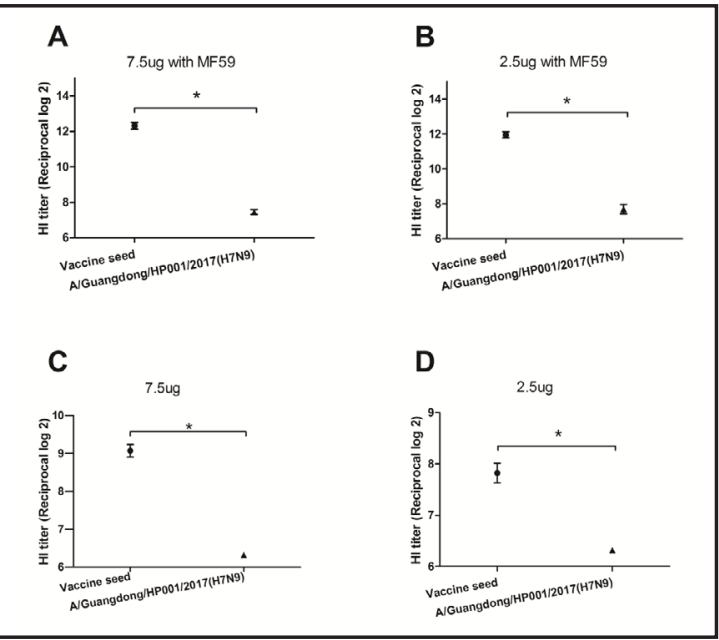

Fig. 1. HI titer measurements of collected serum from different groups. The HI titer was detected by its action on both A/Guangdong/HP001/2017(H7N9) and the vaccine seed. Each dot represents the geometric mean titer (GMT) for groups of 8 mice. Mice received intraperitoneal injection twice with various dosages of the following immune formulations. A: $7.5 \mu \mathrm{g}$ HA with MF59; B: $2.5 \mu \mathrm{g}$ HA with MF59; C: $7.5 \mu \mathrm{g}$ HA; D: $2.5 \mu \mathrm{g}$ $\mathrm{HA} ;{ }^{*} \mathrm{P}<0.05$.

Table 1. The collection of serum after H7N9 vaccination. Note: w/o denotes without

\begin{tabular}{|c|c|c|c|c|c|}
\hline $\begin{array}{l}\text { Immunization } \\
\text { Components }\end{array}$ & $\begin{array}{l}\text { Group } \\
\text { No. }\end{array}$ & HA content & Adjuvant & $\begin{array}{c}\text { Immunization } \\
\text { program }\end{array}$ & $\begin{array}{c}\text { Serum } \\
\text { acquisition time }\end{array}$ \\
\hline Adjuvant vaccine & A & 7.5ug/mouse & $\begin{array}{c}\text { MF59 } \\
0.25 \mathrm{ml} / \text { mouse }\end{array}$ & $\begin{array}{l}\text { intraperitoneal } \\
\text { injection/twice }\end{array}$ & $\begin{array}{l}14 \text { days after } \\
\text { second boost }\end{array}$ \\
\hline Adjuvant vaccine & B & $2.5 \mathrm{ug} / \mathrm{mouse}$ & $\begin{array}{c}\text { MF59 } \\
0.25 \mathrm{ml} / \text { mouse }\end{array}$ & $\begin{array}{l}\text { intraperitoneal } \\
\text { injection/twice }\end{array}$ & $\begin{array}{l}14 \text { days after } \\
\text { second boost }\end{array}$ \\
\hline Split vaccine & C & 7.5ug/mouse & $w / o$ & $\begin{array}{l}\text { intraperitoneal } \\
\text { injection/twice }\end{array}$ & $\begin{array}{l}14 \text { days after } \\
\text { second boost }\end{array}$ \\
\hline Split vaccine & D & $2.5 \mathrm{ug} / \mathrm{mouse}$ & $\mathrm{w} / \mathrm{o}$ & $\begin{array}{l}\text { intraperitoneal } \\
\text { injection/twice }\end{array}$ & $\begin{array}{l}14 \text { days after } \\
\text { second boost }\end{array}$ \\
\hline
\end{tabular}


$(\mathrm{P}<0.05)$. The results showed that the HA structure of highly pathogenic H7N9 has changed. The neutralization of serum decreased as noted by its action on highly pathogenic H7N9.

At the same time, we compared the HI titer induced by different immune dose regimens of split vaccine, with or without MF59 (Fig. 2). We observed that antibody titers were nearly the same even though different amounts of HA antigen $(2.5 \mu \mathrm{g}$ and $7.5 \mu \mathrm{g})$ were used without adjuvant. The antibody titers dramatically increased when different amounts of HA antigen $(2.5 \mu \mathrm{g}$ and $7.5 \mu \mathrm{g})$ were used in combination with MF59 adjuvant $(\mathrm{P}<0.05)$. Using $2.5 \mu \mathrm{g}$ and $7.5 \mu \mathrm{g}$ HA with MF59 adjuvant caused similar antibody responses. Fortunately, the serum collected under both regimens was enough to neutralize highly pathogenic $\mathrm{H} 7 \mathrm{~N} 9$ in vitro. As an adjuvant, MF59 can robustly augment the immune response. H7N9 vaccine adjuvanted with MF59 was much better at protecting against infection with highly pathogenic H7N9 in vitro than $\mathrm{H} 7 \mathrm{~N} 9$ vaccine alone.

\section{The protective effect of vaccine in vivo}

We observed illness, weight loss, and death in the immunized mice after wild type H7N9 challenge (Table 2). Various degrees of weight change were noted in all 5 groups (Fig. 3). The mice in group 4 challenged with A/Zhejiang/DTID-ZJU01/2013(H7N9) presented with mild illness and weight loss in the first 6 days. In the following period, mice recovered with increase in body weight. The mice in group 3 presented with a relatively acute clinical process, and showed inactivity, ruffled fur, poor appetite and an average weight loss of 9.3\% 4 days post-infection. The state of the mice gradually deteriorated over the following days. Five days after post-infection, and half of the mice in group 3 had died. By days 6 postinfection, the remaining mice presented with severe signs of respiratory disease, including respiratory distress and further lack of appetite, and 20\% weight loss. The mice in group 2 were normal during the entire observation period with no obvious weight loss or illness. The mice in group 1 suffered mild illness in the first 4 days but recovered quickly. During the following observation period, mice in group 1 had normal appearance with no obvious weight loss or illness.

Histopathology of lung tissues was evaluated by HE staining. The extent and characteristics of the lesions varied among these groups a week after virus inoculation (Fig. 4). The mice in group 3 had severe multifocal interstitial inflammatory hyperemia and exudative pathological changes in the lung, with larger lesions in the lung tissue, and fusion of multiple patchy lesions. The mice in group 4 only suffered a moderate lesion. The mice in group 1 and group 2 were well protected with minimal lesions. Immunohistochemical staining of lungs exhibited various degrees of injury in each groups one week after virus inoculation (Fig. 4). Viral antigens could be detected in the lung, especially in the bronchiolar epithelium.

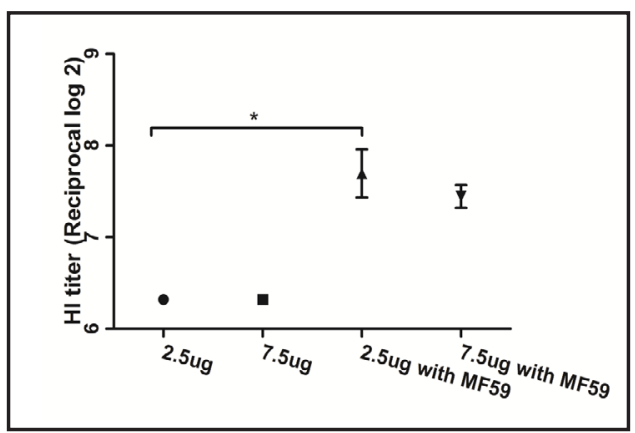

Fig. 2. The HI titer was detected by its action on A/Guangdong/HP001/2017(H7N9). Mice received intraperitoneal injection twice with various dosages of the following immune formulations: $2.5 \mu \mathrm{g} \mathrm{HA} ; 7.5 \mu \mathrm{g} \mathrm{HA} ; 2.5 \mu \mathrm{g} \mathrm{HA}$ with MF59; $7.5 \mu \mathrm{g}$ HA with MF59. ${ }^{*} \mathrm{P}<0.05$.

Table 2. Experiment grouping design. Note: w/o denotes without

\begin{tabular}{|c|c|c|c|c|}
\hline $\begin{array}{l}\text { Immunization } \\
\text { Components }\end{array}$ & Group No. & HA content & Adjuvant & Challenge virus \\
\hline Split H7N9 vaccine & 1 & $2.5 \mathrm{ug} / \mathrm{mouse}$ & $\mathrm{w} / \mathrm{o}$ & A/Guangdong/HP001/2017(H7N9) \\
\hline Adjuvant vaccine & 2 & $2.5 \mathrm{ug} / \mathrm{mouse}$ & $\begin{array}{c}\text { MF59 } \\
0.25 \mathrm{ml} / \text { mouse }\end{array}$ & A/Guangdong/HP001/2017(H7N9) \\
\hline PBS & 3 & $\mathrm{w} / \mathrm{o}$ & w/o & A/Guangdong/HP001/2017(H7N9) \\
\hline PBS & 4 & $\mathrm{w} / \mathrm{o}$ & $\mathrm{w} / \mathrm{o}$ & $\begin{array}{c}\text { A/Zhejiang/DTID- } \\
\text { ZJU01/2013(H7N9) }\end{array}$ \\
\hline PBS & 5 & $\mathrm{w} / \mathrm{o}$ & $\mathrm{w} / \mathrm{o}$ & PBS \\
\hline
\end{tabular}


The mice in group 3 suffered severe injury with a large number of viral antigens detected (Fig. 4). Based on the microscopic lesions, the mice were protected by vaccine during highly pathogenic H7N9 challenge. MF59 adjuvant vaccine was more effective than split vaccine in protecting mice.

The amount of virus was evaluated by quantitative PCR. The virus was clearly detected in the lungs of mice in group 3 . The virus was almost undetectable in group 1 and group 2 (Fig. 5). The mice were protected by the vaccine during highly pathogenic H7N9 challenge.

\section{Evaluation of antibody responses}

After the first vaccination, all HI GMTs (Geometric mean titres) in the groups immunized with HA antigen (H7N9 vaccine with adjuvant or not) were less than 80 , while all MN titers were below 20. After the second boost, titers of $\mathrm{HI}, \mathrm{MN}$, and IgG of groups immunized with vaccine increased substantially (Fig. 6). By comparing the vaccine with or without MF59, we observed that MF59 adjuvant significantly increased the immune response after the second boost. After the second boost, the GMTs of HI titers in group 1 was 40 , while the GMTs of MN titers in group 1 was 14, and the GMTs of IgG titers in group 1 was 40317. While the the titers of HI in group 2 was 160 , the GMTs of MN titers in group 2 was 56 , and the GMTs of IgG titers in group 2 was 512000 . The titers of $\mathrm{HI}, \mathrm{MN}$, and IgG in group 2 were significantly higher than those of group $1(\mathrm{P}<0.05)$. After challenge with highly pathogenic virus, the titers of $\mathrm{HI}, \mathrm{MN}$, and IgG in group 1 and 2 kept increasing. The high titers of HI, MN, and IgG correlated with excellent protective effects. However, in group 3, there were no antibodies produced before challenge since these mice were unvaccinated. After challenge with highly pathogenic H7N9 virus, the HI titer did not exceed 20 , the MN titer did not exceed 10 , and the IgG in group 3 did

Fig. 4. H\&E staining and immunohistochemical staining of lungs. Different groups of mice showed different degrees of injury in the lung 1 week after virus inoculation (original magnification, 100x). Immunohistochemical staining of lungs exhibited various degrees of injury 1 week after virus inoculation (original magnification, $100 \times$ ). HE: Hematoxylin eosin staining; IHC: Immunohistochemical staining. not exceed 1000. The mice in group 3 failed to produce effective protective responses and all died by the sixth day. 


\section{Discussion}

Since the first H7N9 human case emerged in China in 2013, human cases have appeared every year [3]. H7N9 has caused huge economic and social losses due to its severity. Because of its pandemic potential, candidate vaccine seeds were produced in 2013 [16]. The H7N9 vaccines for poultry use have been formulated to prevent H7N9 viruses circulating in poultry at that time. Meanwhile, the H7N9 vaccine made for human use is currently awaiting clinical trial outcome.

Nearly 5 years have elapsed since the first case of $\mathrm{H7N} 9$, while $\mathrm{H} 7 \mathrm{~N} 9$ infections represent an ongoing public health threat without there being an effective vaccine. The H7N9 virus has caused more than 1600 severe human infections to date [3]. Fortunately, with improved clinical experience, H7N9 mortality has declined from $49 \%$ to $38 \%[7,17]$. However, the mortality rate is still high and unacceptable. Moreover, a fifth H7N9 epidemic began earlier in the season, and had spread to more districts and counties in affected provinces. Worryingly, it involved more confirmed cases than previous epidemics $[18,19]$. The isolation of drug-resistant viruses and emergence of highly pathogenic strains in chickens and humans has become a domestic and international concern [7, 20,21].

The highly pathogenic H7N9 has emerged as an antigenically different strain compared with those of earlier epidemics. Worryingly, by 14 July 2017, the HPAI H7N9 viruses had spread from Guangdong province to at least 12 other provinces within China. H7N9 viruses isolated from 25 human cases were found to be HPAI in nature [1]. Highly pathogenic avian influenza A (H7N9) was also detected at 2 poultry farms in Tennessee, USA [22]. Though the case fatality rate and severity in humans were similar between highly pathogenic and low pathogenic H7N9 strains [2, 23], highly pathogenic H7N9 exhibited a R292K mutation, where an amino acid change had occurred that was known to be associated with neuraminidase inhibitor resistance. This lead to severe and complicated clinical sequelae [5, 24, 25]. The rapid geographical expansion and genetic evolution of the HPAI H7N9 viruses pose a great challenge, not only for poultry production but also for public health [26].

The continuous evolution of the virus poses a long-term threat to public health and the poultry industry. Thus, it is imperative to strengthen prevention and control strategies [7, 24, 26]. Effective control measures, including enhanced surveillance, transmission interventions, and protection of vulnerable groups such as the elderly, are therefore urgently needed. Touching sick or dead poultry has been shown to be an important risk factor for HPAI H7 N9 infections and should be highlighted for the control of future influenza A (H7N9) epidemics 
[18]. A vaccine is the most important method for protection of vulnerable groups and to control H7N9 viruses in China. RLXHAF (Newcastle disease recombinant virus expressing the hemagglutinin of H7N9) was generated to protect chickens against HPAI H7N9. The vaccine provided $80 \%$ protection against HPAI H7N9 challenge [27]. Diverse H7N9 vaccine candidates were generated and positive results were obtained from animal trials. However, only a few have been investigated in clinical trials in human volunteers [16]. Some H7N9 vaccines composed of viral-like particles, subunits, and split-virions have been evaluated in adults [28-33]. Further work should be done to obtain licenses for these vaccines.

In our study, we used a monovalent inactivated split vaccine that was produced from the H7N9/PR8 virus to protect from infection of highly pathogenic H7N9 in mice. Highly pathogenic H7N9 is more virulent than the A/Zhejiang/DTID-ZJU01/2013 (H7N9) strain in mice. Our vaccine based on A/Zhejiang/DTID-ZJU01/2013 (H7N9) is effective in protecting against the highly pathogenic H7N9. The possible mechanism was as follows. Firstly, the surface glycoprotein hemagglutinin is the most important antigen to induce antibodies. The putative $\mathrm{H} 7$ antigenic sites are mainly on the HA globular head [34, 35]. Although with the 4 amino acids inserted into the cleavage site of the hemagglutinin protein, the antigenic sites did not experience significant change. Secondly, the NA is another significant antigen. The antibodies induced by NA provide additional benefit to hemagglutinin-specific immunity and may be an important contributor to the effectiveness of H7N9 vaccines [19]. Two major antigenic regions of NA, the 250-loop and 370/400/430-loop domains were found the same between A/Zhejiang/DTID-ZJU01/2013 (H7N9) and A/Guangdong/HP001/2017(H7N9). Without significant antigenic change, the A/ZJU01/PR8/2013 split H7N9 avian influenza vaccine can still protect the BALB/c mice against highly pathogenic H7N9 infection.

In our study, the MF59 can enhance immune responses of the A/ZJU01/PR8/2013 split H7N9 avian influenza vaccine. The possible mechanisms are as follows. Firstly, our previous study has shown that MF59 can enhance Th-2 cytokines expression which has been proved associated with B cell stimulation and antibody production [8]. Meanwhile, MF59 was identified to induce secretion of chemokines, such as monocyte chemotactic protein 1 , macrophage inhibitory protein- 1 alpha, macrophage inhibitory protein-1 beta, and interleukin-8, which are all involved in cell recruitment from blood into peripheral tissue [36]. The earliest and most abundantly recruited cell type is neutrophils, followed by monocytes, eosinophils and later dendritic cells (DCs) and macrophages. After the recruitment of immune cells into the injection site, MF59 can accelerate and enhance monocyte differentiation into DCs, augment antigen uptake, and facilitate migration of DCs into tissue-draining lymph nodes to prime adaptive immune responses [37-39]. The combination of MF59 adjuvant dramatically improved immunogenicity of the vaccine. At previously, we did the experiment to observe whether seasonal vaccine can protect the H7N9 infection previously. The result showed that the seasonal vaccine doesn't have crossprotective effect on $\mathrm{H} 7 \mathrm{~N} 9$ [8]. We have not done the experiment whether split $\mathrm{H} 7 \mathrm{~N} 9$ vaccine can protect seasonal influenza. However, according to our previous research results and the gene sequence characteristics of H7N9 virus, we believe that the split H7N9 vaccine doesn't have cross-protective effect on seasonal influenza.

In summary, the current H7N9 vaccine based on A/Zhejiang/DTID-ZJU01/2013 (H7N9) is effective in protecting against highly pathogenic H7N9. The H7N9 vaccine adjuvanted with MF59 is better at protecting against infection with highly pathogenic H7N9. As we know, vaccines must undergo strict preclinical safety evaluation before licensing. In order to procure and implement H7N9 vaccine, further clinical trials should be done to evaluate this novel MF59 adjuvanted vaccine. Meanwhile, we should update the vaccine strain based on the highly pathogenic H7N9 gene sequence.

\section{Abbreviations}

HPAI (Highly pathogenic avian influenza); HA (Hemagglutinin); NA (Neuraminidase); MDCK (Madin-Darby canine kidney cell line); ATCC (American Type Culture Collection); HI 
(Hemagglutinininhibition); PBS(Phosphatebuffersolution); PCR(Polymerasechain reaction); TPCK (Toluylsulfonyl -L- amino benzochloromethyl ketone); TMB (Tetramethylbenzidine); $\mathrm{H}_{2} \mathrm{O}_{2}$ (Hydrogen peroxide); SEM (Standard Error of Mean); GMTs (Geometric mean titres); IgG (Immunoglobulin G); TCID50 (Fifty percent tissue culture infective dose); MN (Microneutralization); HE (Hematoxylin eosin staining); IHC (Immunohistological test); Cq (Quantification cycle); w/o (Without); DCs (Dendritic cells).

\section{Acknowledgements}

This work was supported by grants from the State Project for Essential Drug Research and Development (\#2015ZX09101044), and the Science \& Technology Key Program of Zhejiang China (\#2014C03039). The funders had no role in study design, data collection and analysis, decision to publish, or preparation of the manuscript. XX. Wu, DS. Yu and TH. Weng performed the animal experiments. W. Yao provided H7N9 vaccine and MF59 adjuvant. XX. $\mathrm{Wu}, \mathrm{XL}$. Deng, and FY. Hu performed the H7N9 virus isolation. HL. Ou and CY. Hu performed the immunological detection. HP. Yao and XX. Wu performed the statistical analysis. LJ. Li, HP. Yao, FC Zhang and NP. Wu. conceived and directed the project. All authors participated in writing the manuscript.

\section{Disclosure Statement}

One author has declared that the following interests are relevant to the submitted work. Wei Yao is an employee of Zhejiang Tianyuan Bio-Pharmaceutical Co., Ltd. (which was affiliated with GSK Vaccine Inc.). He participated in the production of the H7N9 vaccine and MF59 adjuvant but had nothing to do with the investigation of the study outcomes. The other authors declare that they have no conflicts of interest related to the publication of this manuscript.

\section{References}

1 Yang L, Zhu W, Li X, Chen M, Wu J, Yu P, Qi S, Huang Y, Shi W, Dong J, Zhao X, Huang W, Li Z, Zeng X, Bo H, Chen T, Chen W, Liu J, Zhang Y, Liang Z, Shi W, Shu Y, Wang D: Genesis and Spread of Newly Emerged Highly Pathogenic H7N9 Avian Viruses in Mainland China. J Virol DOI: 10.1128/JVI.01277-17.

- Wang X, Jiang H, Wu P, Uyeki T M, Feng L, Lai S, Wang L, Huo X, Xu K, Chen E, Wang X, He J, Kang M, Zhang R, Zhang J, Wu J, Hu S, Zhang H, Liu X, Fu W, Ou J, Wu S, Qin Y, Zhang Z, Shi Y, Zhang J, Artois J, Fang V J, Zhu H, Guan Y, Gilbert M, Horby P W, Leung G M, Gao G F, Cowling B J, Yu H: Epidemiology of avian influenza A H7N9 virus in human beings across five epidemics in mainland China, 2013-17: an epidemiological study of laboratory-confirmed case series. Lancet Infect Dis 2017;17:822-832.

-3 Subbarao K: Avian influenza H7N9 viruses: a rare second warning. Cell Res DOI: 10.1038/cr.2017.154.

4 Zhang F, Bi Y, Wang J, Wong G, Shi W, Hu F, Yang Y, Yang L, Deng X, Jiang S, He X, Liu Y, Yin C, Zhong N, Gao G F: Human infections with recently-emerging highly pathogenic $\mathrm{H} 7 \mathrm{~N} 9$ avian influenza virus in China. J Infect 2017;75:71-75.

5 Ke C, Mok C K P, Zhu W, Zhou H, He J, Guan W, Wu J, Song W, Wang D, Liu J, Lin Q, Chu D K W, Yang L, Zhong N, Yang Z, Shu Y, Peiris J S M: Human Infection with Highly Pathogenic Avian Influenza A(H7N9) Virus, China. Emerg Infect Dis 2017;23:1332-1340.

6 Qi W, Jia W, Liu D, Li J, Bi Y, Xie S, Li B, Hu T, Du Y, Xing L, Zhang J, Zhang F, Wei X, Eden J S, Li H, Tian H, Li W, Su G, Lao G, Xu C, Xu B, Liu W, Zhang G, Ren T, Holmes E C, Cui J, Shi W, Gao G F, Liao M: Emergence and adaptation of a novel highly pathogenic H7N9 influenza virus in birds and humans from a 2013-humaninfecting low pathogenic ancestor. J Virol DOI: 10.1128/JVI.00921-17. 


\section{Cellular Physiology Cell Physiol Biochem 2018;46:633-643 and Biochemistry Published onlıne: April 04, $2018 \quad \begin{aligned} & \text { DOI: 10.1159/000488631 } 2018 \text { The Author(s). Published by S. Karger AG, Basel } \\ & \text { www.karger.com/cpb }\end{aligned}$}

Wu et al.: h7n9 Vaccine Protects Against Highly Pathogenic H7N9

7 Su S, Gu M, Liu D, Cui J, Gao G F, Zhou J, Liu X: Epidemiology, Evolution, and Pathogenesis of H7N9 Influenza Viruses in Five Epidemic Waves since 2013 in China. Trends Microbiol 2017;25:713-728.

8 Ou H, Yao H, Yao W, Wu N, Wu X, Han C, Cheng L, Chen K, Chen H, Li L: Analysis of the immunogenicity and bioactivities of a split influenza A/H7N9 vaccine mixed with MF59 adjuvant in BALB/c mice. Vaccine 2016;34:2362-2370.

-9 Ou H, Yao W, Wu N, Wang F X, Weng T, Han C, Lu X, Yu D, Wu H, Cheng L, Chen H, Yao H, Li L: Preclinical evaluation of the safety and pathogenicity of a live attenuated recombinant influenza A/H7N9 seed strain and corresponding MF59-adjuvanted split vaccine. Oncotarget 2016;7:81012-81025.

10 Black S: Safety and effectiveness of MF-59 adjuvanted influenza vaccines in children and adults. Vaccine 2015;33 Suppl 2:B3-5.

11 Nakaya H I, Clutterbuck E, Kazmin D, Wang L, Cortese M, Bosinger S E, Patel N B, Zak D E, Aderem A, Dong T, Del Giudice G, Rappuoli R, Cerundolo V, Pollard A J, Pulendran B, Siegrist C A: Systems biology of immunity to MF59-adjuvanted versus nonadjuvanted trivalent seasonal influenza vaccines in early childhood. Proc Natl Acad Sci U S A 2016;113:1853-1858.

12 Durando P, Icardi G, Ansaldi F: MF59-adjuvanted vaccine: a safe and useful tool to enhance and broaden protection against seasonal influenza viruses in subjects at risk. Expert Opin Biol Ther 2010;10:639-651.

13 Banzhoff A, Pellegrini M, Del Giudice G, Fragapane E, Groth N, Podda A: MF59-adjuvanted vaccines for seasonal and pandemic influenza prophylaxis. Influenza Other Respir Viruses 2008;2:243-249.

14 Podda A: The adjuvanted influenza vaccines with novel adjuvants: experience with the MF59-adjuvanted vaccine. Vaccine 2001;19:2673-2680.

15 Ou H, Yao W, Yu D, Weng T, Wang F X C, Wu X, Wu H, Cheng L, Lu X, Wu N, Chen H, Li L, Yao H: Longevity of protective immune responses induced by a split influenza A (H7N9) vaccine mixed with MF59 adjuvant in BALB/c mice. Oncotarget 2017;8:91828-91840.

16 Hu Z, Jiao X, Liu X: Antibody Immunity Induced by H7N9 Avian Influenza Vaccines: Evaluation Criteria, Affecting Factors, and Implications for Rational Vaccine Design. Front Microbiol DOI: 10.3389/ fmicb.2017.01898.

17 Gao H N, Lu H Z, Cao B, Du B, Shang H, Gan J H, Lu S H, Yang Y D, Fang Q, Shen Y Z, Xi X M, Gu Q, Zhou X M, Qu H P, Yan Z, Li F M, Zhao W, Gao Z C, Wang G F, Ruan L X, Wang W H, Ye J, Cao H F, Li X W, Zhang W H, Fang X C, He J, Liang W F, Xie J, Zeng M, Wu X Z, Li J, Xia Q, Jin Z C, Chen Q, Tang C, Zhang Z Y, Hou B M, Feng Z X, Sheng J F, Zhong N S, Li L J: Clinical findings in 111 cases of influenza A (H7N9) virus infection. N Engl J Med 2013;368:2277-2285.

18 Wu H, Wang X, Xue M, Xue M, Wu C, Lu Q, Ding Z, Xv X, Lin J: Spatial characteristics and the epidemiology of human infections with avian influenza A(H7N9) virus in five waves from 2013 to 2017 in Zhejiang Province, China. PLoS One DOI: 10.1371/journal.pone.0180763.

-19 Wan H, Qi L, Gao J, Couzens L K, Jiang L, Gao Y, Sheng Z M, Fong S, Hahn M, Khurana S, Taubenberger J K, Eichelberger M C: Comparison of the Efficacy of N9 Neuraminidase-specific Monoclonal Antibodies against Influenza A(H7N9) Virus Infection. J Virol DOI: 10.1128/JVI.01588-17.

-20 Danqi B, Li Z, Liu Q Richt J A: H7N9 avian influenza A virus in China: a short report on its circulation, drug resistant mutants and novel antiviral drugs. Expert Rev Anti Infect Ther 2017;15:723-727.

-21 Chen J, Zhang J, Zhu W, Zhang Y, Tan H, Liu M, Cai M, Shen J, Ly H, Chen J: First genome report and analysis of chicken H7N9 influenza viruses with poly-basic amino acids insertion in the hemagglutinin cleavage site. Sci Rep DOI: 10.1038/s41598-017-10605-6.

-22 Lee D H, Torchetti M K, Killian M L, Berhane Y, Swayne D E: Highly Pathogenic Avian Influenza A(H7N9) Virus, Tennessee, USA, March 2017. Emerg Infect Dis DOI: 10.3201/eid2311.171013.

-23 Kang M, Lau E H Y, Guan W, Yang Y, Song T, Cowling B J, Wu J, Peiris M, He J, Mok C K P: Epidemiology of human infections with highly pathogenic avian influenza A(H7N9) virus in Guangdong, 2016 to 2017. Euro Surveill DOI: 10.2807/1560-7917.ES.2017.22.27.30568.

24 Deng Y, Li C, Han J, Wen Y, Wang J, Hong W, Li X, Liu Z, Ye Q, Li J, Zhou C, Yu L, Qin C, Zhang F, Jiang T: Phylogenetic and genetic characterization of a 2017 clinical isolate of H7N9 virus in Guangzhou, China during the fifth epidemic wave. Sci China Life Sci DOI: 10.1007/s11427-017-9152-1. 


\section{Cellular Physiology Cell Physiol Biochem 2018;46:633-643 \begin{tabular}{l|l} 
DOI: 10.1159/000488631 & Ond Biochemistry 2018 The Author(s). Published by S. Karger AG, Basel \\
www.karger.com/cpb
\end{tabular}}

Wu et al.: h7n9 Vaccine Protects Against Highly Pathogenic H7N9

25 Kile J C, Ren R, Liu L, Greene C M, Roguski K, Iuliano A D, Jang Y, Jones J, Thor S, Song Y, Zhou S, Trock S C, Dugan V, Wentworth D E, Levine M Z, Uyeki T M, Katz J M, Jernigan D B, Olsen S J, Fry A M, AzzizBaumgartner E, Davis C T: Update: Increase in Human Infections with Novel Asian Lineage Avian Influenza A(H7N9) Viruses During the Fifth Epidemic - China, October 1, 2016-August 7, 2017. MMWR Morb Mortal Wkly Rep 2017;66:928-932.

26 Ding X, Luo J, Quan L, Wu A, Jiang T: Evolutionary genotypes of influenza A (H7N9) viruses over five epidemic waves in China. Infect Genet Evol 2017;55:269-276.

27 Hu Z, Liu X, Jiao X, Liu X: Newcastle disease virus (NDV) recombinant expressing the hemagglutinin of H7N9 avian influenza virus protects chickens against NDV and highly pathogenic avian influenza A (H7N9) virus challenges. Vaccine 2017;35:6585-6590.

28 Madan A, Segall N, Ferguson M, Frenette L, Kroll R, Friel D, Soni J, Li P, Innis B L, Schuind A: Immunogenicity and Safety of an AS03-Adjuvanted H7N9 Pandemic Influenza Vaccine in a Randomized Trial in Healthy Adults. J Infect Dis 2016;214:1717-1727.

29 Jackson L A, Campbell J D, Frey S E, Edwards K M, Keitel W A, Kotloff K L, Berry A A, Graham I, Atmar R L, Creech C B, Thomsen I P, Patel S M, Gutierrez A F, Anderson E L, El Sahly H M, Hill H, Noah D L, Bellamy A R: Effect of Varying Doses of a Monovalent H7N9 Influenza Vaccine With and Without AS03 and MF59 Adjuvants on Immune Response: A Randomized Clinical Trial. JAMA 2015;314:237-246.

-30 Mulligan M J, Bernstein D I, Winokur P, Rupp R, Anderson E, Rouphael N, Dickey M, Stapleton J T, Edupuganti S, Spearman P, Ince D, Noah D L, Hill H, Bellamy A R: Serological responses to an avian influenza A/H7N9 vaccine mixed at the point-of-use with MF59 adjuvant: a randomized clinical trial. JAMA 2014;312:1409-1419.

-31 Bart S A, Hohenboken M, Della Cioppa G, Narasimhan V, Dormitzer P R, Kanesa-Thasan N: A cell culturederived MF59-adjuvanted pandemic A/H7N9 vaccine is immunogenic in adults. Sci Transl Med DOI: 10.1126/scitranslmed.3008761.

-32 Fries L F, Smith G E, Glenn G M: A recombinant viruslike particle influenza A (H7N9) vaccine. N Engl J Med 2013;369:2564-2566.

33 Wu U I, Hsieh S M, Lee W S, Wang N C, Kung H C, Ou T Y, Chen F L, Lin T Y, Chen Y C, Chang S C: Safety and immunogenicity of an inactivated cell culture-derived H7N9 influenza vaccine in healthy adults: A phase I/ II, prospective, randomized, open-label trial. Vaccine 2017;35:4099-4104.

-34 Henry Dunand C J, Leon P E, Huang M, Choi A, Chromikova V, Ho I Y, Tan G S, Cruz J, Hirsh A, Zheng N Y, Mullarkey C E, Ennis F A, Terajima M, Treanor J J, Topham D J, Subbarao K, Palese P, Krammer F, Wilson P C: Both Neutralizing and Non-Neutralizing Human H7N9 Influenza Vaccine-Induced Monoclonal Antibodies Confer Protection. Cell Host Microbe 2016;19:800-813.

-35 Tsuchiya E, Sugawara K, Hongo S, Matsuzaki Y, Muraki Y, Li Z N, Nakamura K: Antigenic structure of the haemagglutinin of human influenza A/H2N2 virus. J Gen Virol 2001;82:2475-2484.

-36 Seubert A, Monaci E, Pizza M, O'Hagan D T, Wack A: The adjuvants aluminum hydroxide and MF59 induce monocyte and granulocyte chemoattractants and enhance monocyte differentiation toward dendritic cells. J Immunol 2008;180:5402-5412.

-37 Mastelic Gavillet B, Eberhardt C S, Auderset F, Castellino F, Seubert A, Tregoning J S, Lambert P H, de Gregorio E, Del Giudice G, Siegrist C A: MF59 Mediates Its B Cell Adjuvanticity by Promoting T Follicular Helper Cells and Thus Germinal Center Responses in Adult and Early Life. J Immunol 2015;194:4836-4845.

-38 Calabro S, Tortoli M, Baudner B C, Pacitto A, Cortese M, O'Hagan D T, De Gregorio E, Seubert A, Wack A: Vaccine adjuvants alum and MF59 induce rapid recruitment of neutrophils and monocytes that participate in antigen transport to draining lymph nodes. Vaccine 2011;29:1812-1823.

39 Baudner B C, Ronconi V, Casini D, Tortoli M, Kazzaz J, Singh M, Hawkins L D, Wack A, O'Hagan D T: MF59 emulsion is an effective delivery system for a synthetic TLR4 agonist (E6020). Pharm Res 2009;26:14771485. 